\title{
MESENCHYMAL STEM CELLS: AN INNOVATIVE APPROACH IN PHARMACOKINETICS
}

\author{
SEEMA TRIPATHY*, PRAFULLA KUMAR MOHANTY
}

Department of Zoology, Utkal University, Vani Vihar, Bhubaneswar, Odisha, India. Email: seema.tripathy@yahoo.com

\author{
Received: 03 November 2016, Revised and Accepted: 15 December 2016
}

\begin{abstract}
Multipotent mesenchymal stem cells (MSCs) are special kind of stem cells which originate from mesenchyme. These cells can be used as an imperative tool to study reproductive toxicity, carcinogenicity, mutagenicity, genotoxicity, and pharmacokinetics. This novel system may reveal toxicantinduced etiology, decipher detailed understanding on molecular mechanisms of toxicants induced pathways and also enumerate the safe dose of an investigational product. Hence, this could ultimately replace, improve or overtake current predictive models in toxicology. The particular review describes the utilization of MSCs in different field of toxicological and pharmacological research.
\end{abstract}

Keywords: Mesenchymal stem cells, Toxicant, Etiology, Pharmacokinetics.

(C) 2017 The Authors. Published by Innovare Academic Sciences Pvt Ltd. This is an open access article under the CC BY license (http://creativecommons. org/licenses/by/4. 0/) DOI: http://dx.doi.org/10.22159/ajpcr.2017.v10i3.16023

\section{INTRODUCTION}

Toxicity may result due to administration or exposure to drugs or chemicals or xenobiotic compounds or radiation or particulate matter or endogenous production of toxins by any microbial flora or transplanted cells. Such primary and auxiliary toxic agents may disrupt intracellular cell signaling and interrupt cell-tocell interactions from intra- and extra-cellular communiqué and affect cellular architectures in biochemical, anatomical, cellular, psychological, and pathological level. This may be due to the complex interaction established between toxic agents and genes, proteins, RNA and cellular organelles [1,2]. These phenomena may alter biological cascades of circadian rhythm in human, affect the dynamic cellular function and metabolism, generate malignant tissues, change rhythmic beating passion of heart and can provoke psychological complications [3]. In the pharmaceutical settings, toxicological studies of new compounds or agents play the most key role to provide safety and accurate assessment of risk factors associated with novel drugs before administration to human beings. The US Food and Drug Administration states that it is essential to screen new molecules for pharmacological activity and toxicity potential in animals (21CFR Part 314) [4]. Traditionally, various animal models such as mice, rats, guinea pigs, and dogs are used to predict or anticipate toxicity of newly synthesized drugs or stringent chemicals or any suspected agents, as these agents might induce cardiotoxicity, hepatotoxicity, genotoxicity or epigenetic and reproductive toxicity in humans. However, there are several demerits of using animals in toxicological studies. The tests conducted in animal models are not yet well standardized. Apart from this, the animal models are not good representative of humans because inter-specific differences exist in accordance to pharmacokinetics and toxicokinetics background [5]. It often gives doubtful results during early (preclinical) or necessary late (clinical) assessment of newly synthesized drugs leading to termination of drug development programs (Fig. 1).

The ethical issues and cost of analysis add further constrain in the use of animals in toxicological studies. To reduce the risk and ambiguity that is often associated with testing, developing and screening of toxicity using experimental animals currently, suitable alternative in vitro models such as whole embryo cultures, primary cultures and permanent cell lines, cell lines established from specialized somatic cells are being used [7]. These biological systems may produce relevant and accurate information about toxic agents affecting the vital cellular functions. This may be due to the fact that common cellular sources are used to test the subject (suspected agents) and to see the effects [8]. Recently, the novel approach of using stem cell derived systems of embryonic origin such as embryonic carcinoma, embryonic stem (ES) and embryonic germ cells (GCs) and non-embryonic origin induce pluripotent cells (iPSc) and multipotent adult stem (AS) cells open new avenues in the field of pharmacokinetics and toxicological research [6]. These in vitro systems are now being used to extrapolate the correlation between toxic effects of toxicants and the doses causing organ toxicity, embryotoxicity and developmental toxicity (Fig. 2) so that a safe predetermined dose of chemicals can be prescribed before in vivo studies and clinical translation. This review describes the nontherapeutic potential applications of multipotent mesenchymal stem cells (MSCs), in particular, case pertaining to toxicological studies and pharmacological screening

\section{LETHALITY-INDUCED BY TOXIC AGENTS}

The toxic agents target constituent of tissues by altering enzyme activity, interfering the binding of hormone to a specific receptor by creating structural homolog to alter its function, modulating the number of hormone receptors, changing the way of hormone synthesis and their affinities for specific molecules. Intercalation with nucleic acids, disturbances in electrolyte balance and the disorganization of cellular water and membrane lipids are illustrated as toxic processes involving ionic or van der Waals forces. The interaction results perturbation of biological pathways. When perturbations are sufficiently large or when the host is unable to adapt to the changed physiological conditions, it may contribute to nutritional, genetic, disease, or lifestage status factors. The biological function is compromised, and this leads to toxicity and disease. The circuitry affected by the chemical is expected to determine the shapes of curves of dose-response relationships for these perturbations. The responses are viewed as the results of an intersection of exposure and biological function. Hence, the determination of lethal doses that result progressive activation of toxicity pathways from perturbation of initial targets, through activation of stress controlling pathways, to overtly toxic responses (apical endpoints) is essential [9]. Traditionally, to determine toxicity, the LD50 assay has been used, which is a measure of the dose required to cause death in $50 \%$ of the animals under the study. An alternative to this assay was first suggested by the British Toxicology Society in 1984 and was based on administering a series of fixed doses and relying on the observation of clear signs of toxicity (altered morphology, biochemistry, and undesired by-products) rather than the endpoint of the assay being death. Recently, developed in vitro signatures and 
computational models are being used to determine agents that induce toxicity, detect perturbation in cellular pathways that are expected to contribute to or result in adverse health effects. Pathway testing would require a suite of tests which could identify the range of significant perturbations of human biology. This might occur as a result of chemical exposure (Fig. 3)

\section{STEM CELLS AND THEIR RESPONSE TO TOXICITY}

The development of multicellular organism from egg to an adult is a complex series of interlocked events, which depends on precise coordination of time and space. From the time of implantation of totipotent zygote, the complex interaction between external environment and physiological stress results in a dynamic changeover from totipotent stem cells to pluripotent stem cells and multipotent stem cells that commit to form specific organ types. These mutually exclusive events are directed via differentiation, determination, and specification which ultimately result in the formation of an adult individual. Stem cells are uncommitted cells [10]. These cells are an important tool to study molecular mechanisms of different biological pathways, differentiation, and mechanisms of cellular commitment [11]. These are ideal experimental systems for the study of molecular events of development and analysis of agents that may alter these directed mechanisms. Stem cells can facultatively use both symmetric and asymmetric divisions to express constitutively the properties of selfrenewal and differentiation (Fig. 4).

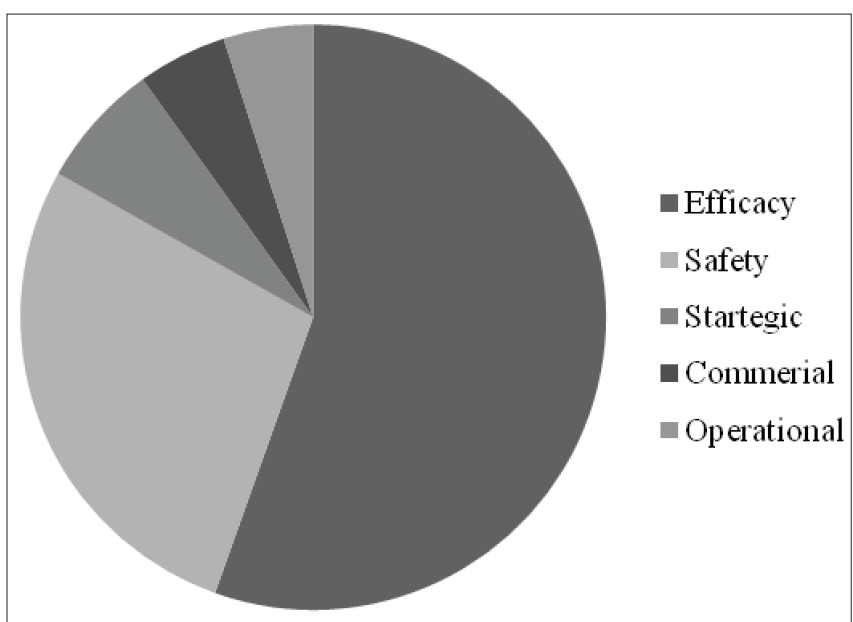

Fig. 1: Important causes of drugs failure (Data obtained from Suter-Dick et al. [6])
Symmetric divisions can expand stem-cell number by generating daughter cells that are destined to acquire the same fate thus, playing an important role in adult mammalian homeostasis. Asymmetric divisions result cells that are destined to acquire a different fate. It is noteworthy that asymmetric divisions can be governed by both intrinsic partitioning of fate regulators and asymmetric exposure to extrinsic cues [12]. ES cells derived from early embryonic cells represent an excellent in vitro model system to study the molecular mechanism associated with pluripotency, self-renewal and development. The remarkable capacity of ES cells to transform into variety of somatic and germinal cells reflects the dynamic events that occur in vivo [13]. ES cell lines were first derived from mice $[14,15]$ but currently available from a variety of mammalian systems, including human [16]. They can propagate at undifferentiated state up to indefinite period under defined culture conditions $[13,14,17]$. The most reliable method for generating differentiated cells from ES cells is by induction of embryoid bodies (EBs). Many features of EBs resemble that of developing embryo. These EBs on attachment to permissive surface like gelatin, collagen, and treatment with appropriate inducer continue a programed differentiation into ectodermal, mesodermal, and endodermal lineages [18]. Hence, pluripotent ES cell lines recapitulate cellular developmental processes and gene expression patterns of early embryogenesis during in vitro differentiation which is hard to visualize in in vivo condition. Thus, ES cells hold great promise as an unlimited cell source for various clinical and biotechnological applications [19-21]. This disease-in-adish model is useful to understand molecular mechanisms of diseases and cellular responses to various therapeutic and toxic agents. Hence, in vitro culture of human ES (hES) cells is a suitable system to study etiology and prognosis of many degenerative diseases and a valuable tool for drug or toxicity screening and mechanistic studies including analysis of disease pathway and developmental toxicity [22]. Developmental toxicity is often associated with birth defects, low birth weight, and biological dysfunction. About $10 \%$ of birth defects are related with environmental factors including therapeutic agents and developmental toxicants [23]. Embryotoxicity can be assessed by ES cell test using differentiated cells of mouse ES cells. The test is successfully validated by the European Center for the validation of alternative methods (ECVAM) and considered as fundamental models to screen the unknown chemicals capable of causing embryotoxicity, such as cytotoxicity and differentiation and to know the altered physiological mechanisms caused due to toxicity from molecular level. In addition, differences in sensitivity between differentiated (adult) and embryonic cells are also taken into consideration. To predict the embryotoxic potential of a test substance, three endpoints are assessed such as the inhibition of differentiation into beating cardiomyocytes, the cytotoxic effects on stem cells, and the cytotoxic effects on 3T3 fibroblasts. A special feature of the EST is that it is

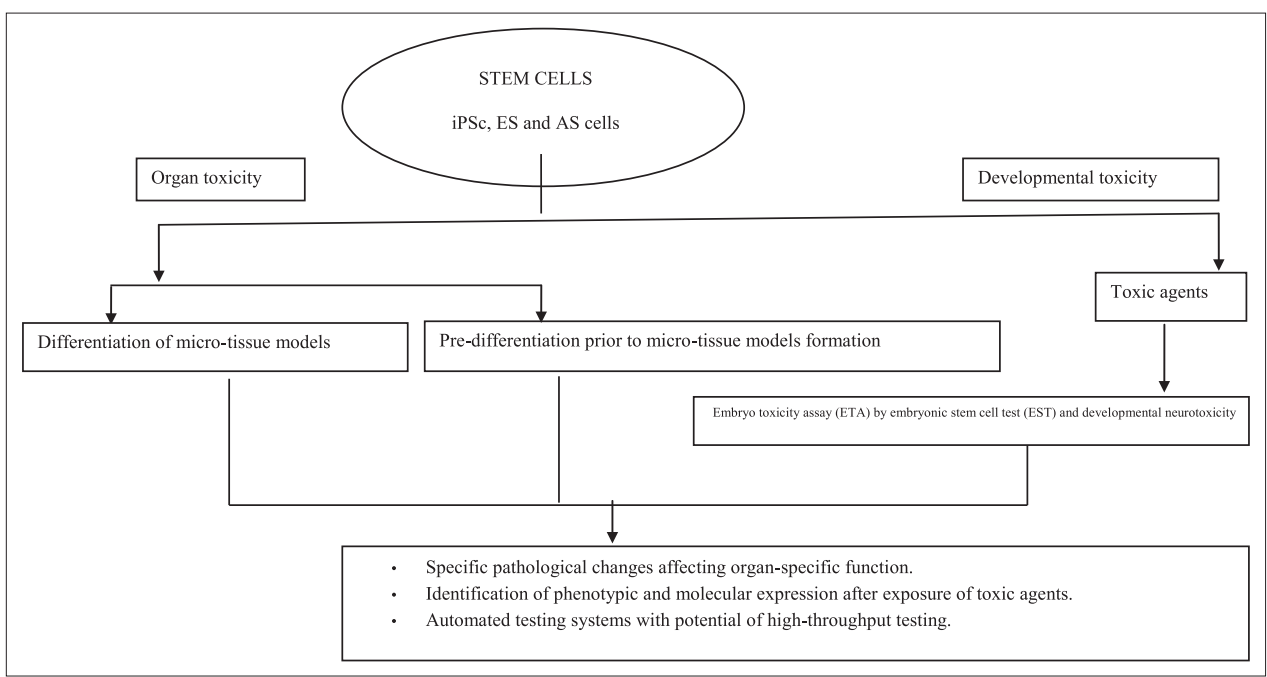

Fig. 2: Potential application of embryonic and adult stem cells to design toxicologically relevant organotypic microtissue models 


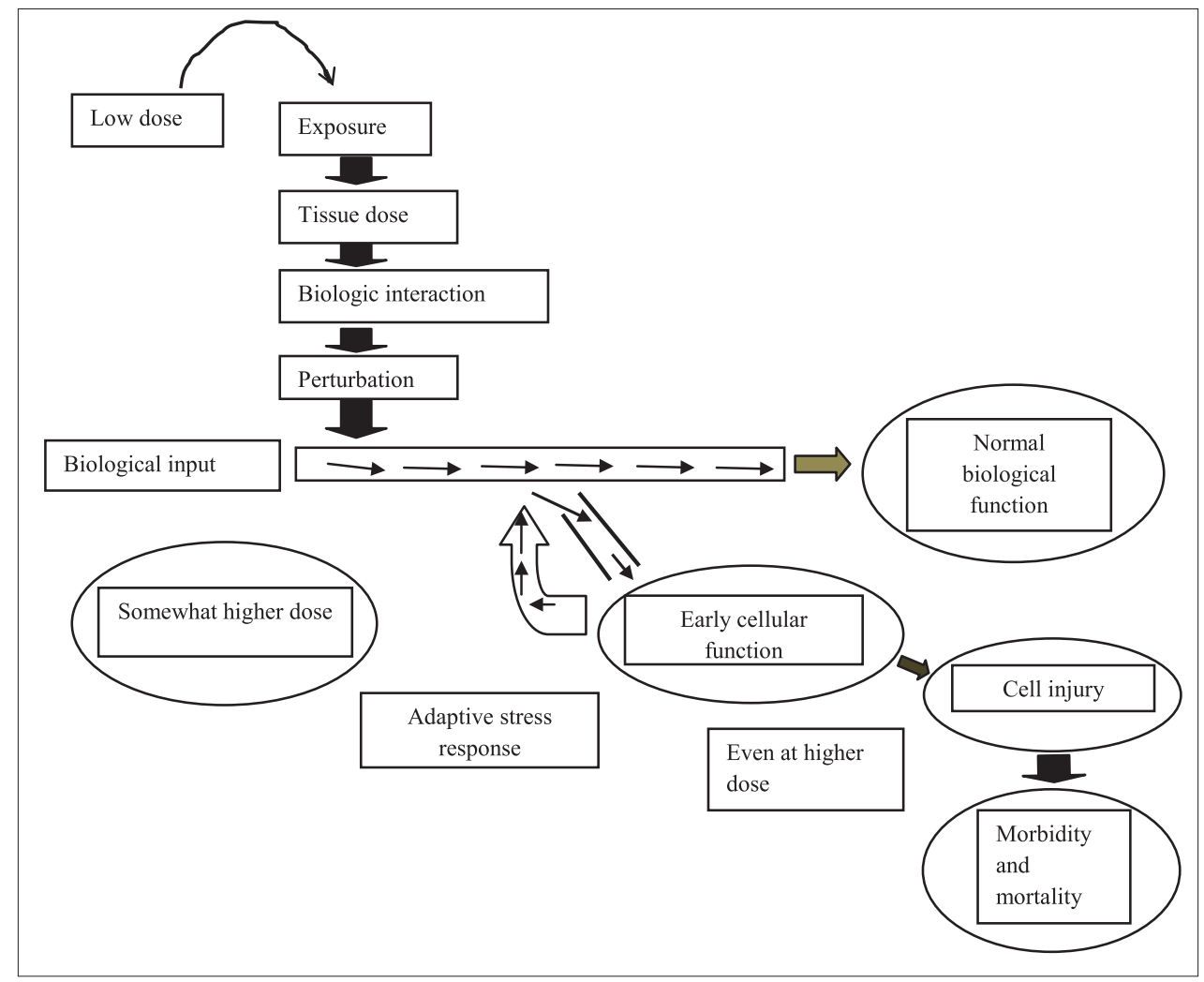

Fig. 3: Relationship between dose and toxicity

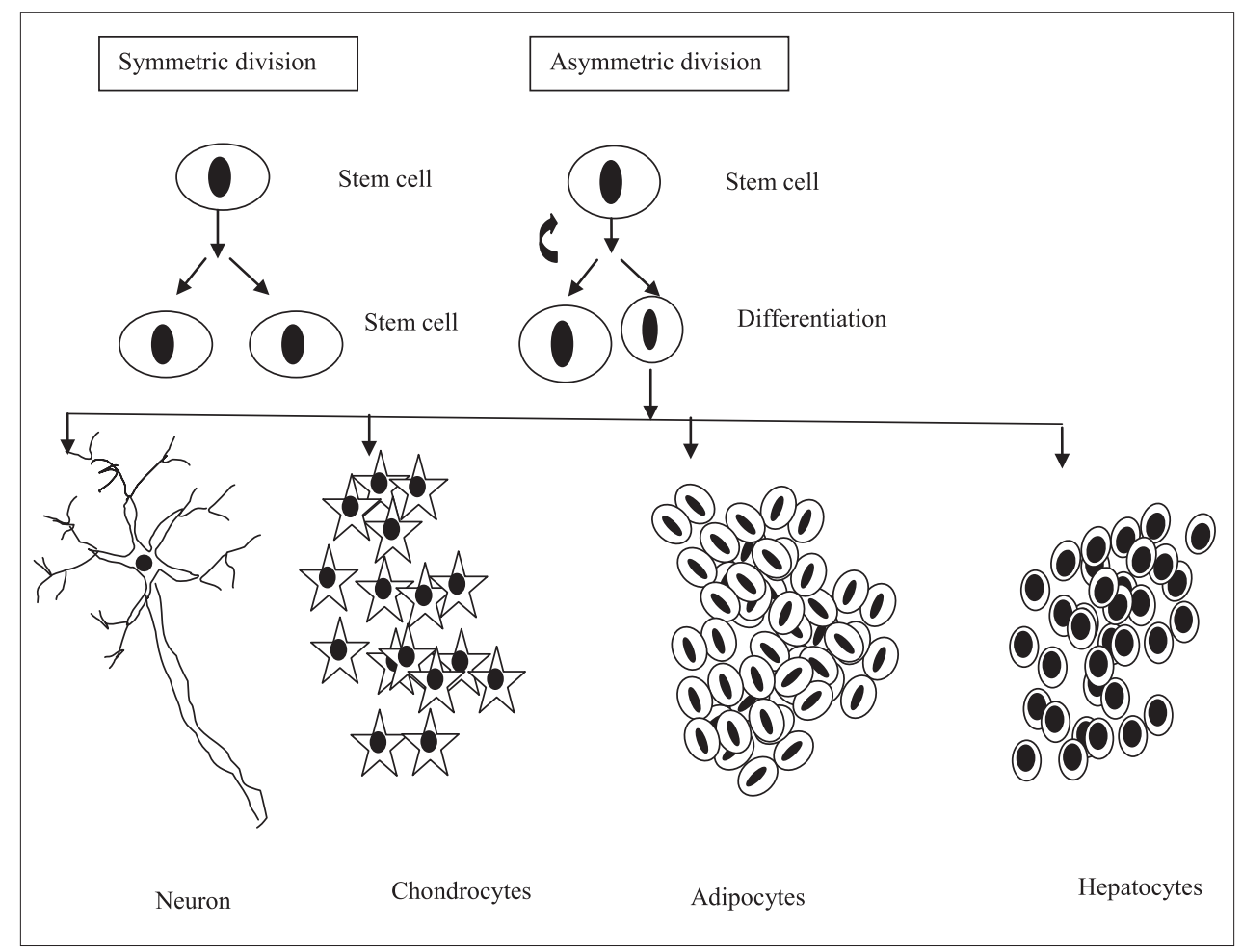

Fig. 4: Division and differentiation shown by stem cells

solely based on permanent cell lines so that primary embryonic cells and tissues from pregnant animals are not needed. This EST protocol is an ECVAM-validated method, in which the morphological assessment of contracting cardiomyocytes is used as endpoint for differentiation, and the molecular-based fluorescent-activated cell sorting-EST method, in which highly predictive protein markers specific for developing heart tissue are selected. With these methods, the embryotoxic potency of a compound can be assessed in vitro within 10 or 7 days, respectively [24]. Available literature suggests that this in vitro cultured ES cells model is currently considered as the best model to predict embryotoxicity, developmental toxicity, mutagenicity, and teratogenicity (Fig. 5). 


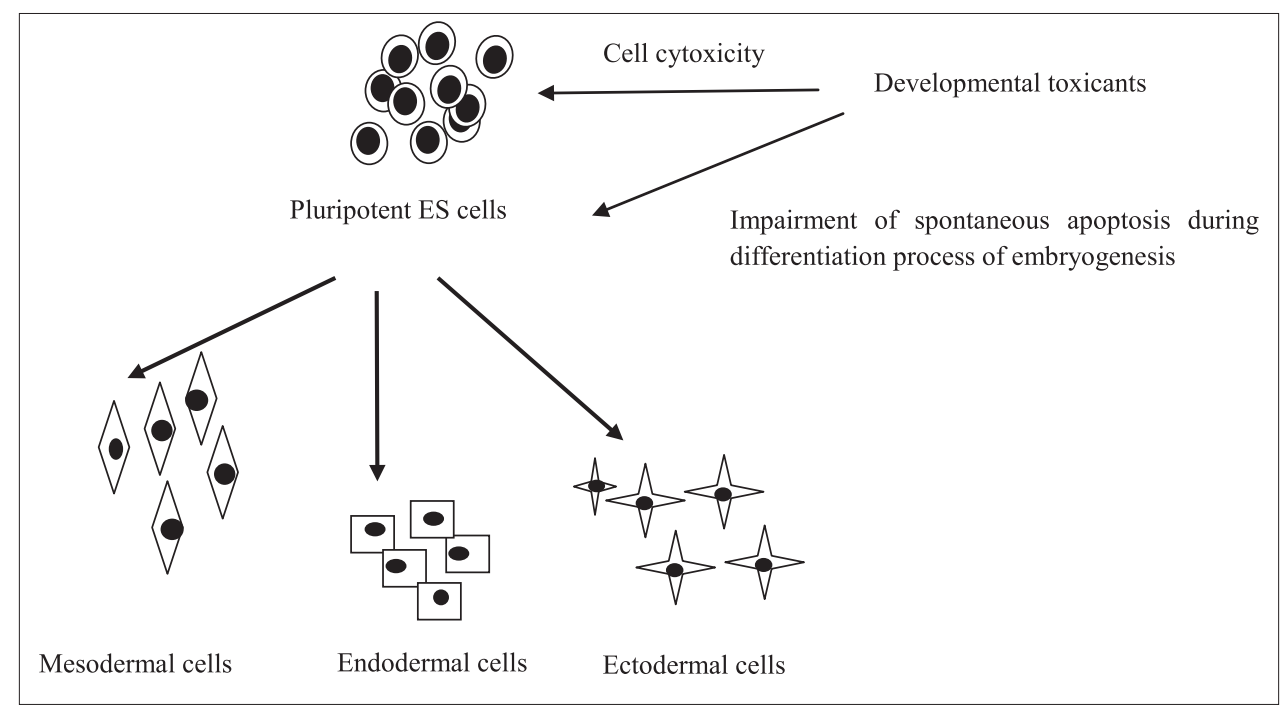

Fig. 5: ES cell derived differentiation-related endpoints using developmental toxicants

Recent studies demonstrate that endocrine disruptors (EDs) may be any estrogen-like and antiandrogenic chemicals, environmental agents [e.g., polychlorinated biphenyls (PCBs), dichlorodiphenyltrichloroethane (DDT), dioxin, and some pesticides) can affect function of reproductive cells (GCs) and organs or tissues associated with reproduction. The compounds such as bisphenol-A, di-2-ethylhexyl phthalate (DEHP) and dibutyl phthalate, vinclozolin promote epigenetic transgenerational inheritance into subsequent generations [25]. Hence, extensive screening and multi-generation studies are required prior to registration of agrochemicals and before commercialization of pharmaceutical products. Currently, ES cells are not only used to test chemical compounds but also to identify the toxic effects of physical factors, such as electromagnetic fields emitted by digital mobile communication systems [26]. Despite several advantages, application of ES cells in biomedical research is often restricted due to ethical and social issues. To circumvent this problem, human-iPSCs are generated by reprograming the somatic cells and AS cells derived from several adult origin are currently being used. iPSCs are converted pluripotent stem cells. In this process, the adult somatic cells are "forced" to express five pivotal genes, namely Oct-3/4, SOX2, c-Myc, Klf4, and Nanog essential to maintain pluripotency [27] that are silenced in course of development. Currently, they play a key role in therapeutic and other biotechnological applications such as drug discovery, toxicology, disease modeling, and gene therapy [28]. It is demonstrated that iPSCs are currently being used for high-throughput screening and chronic toxicity assessment of cardiac, hepatic, and nervous tissues [29]. Recent report by Deshmukh et al. [30] describes that ES cells and iPSCs are efficiently used to screen cardiac and neurotoxic agents. iPSCs derived from different somatic cells may be used to produce unrepaired somatic cells for disease modeling or drug screening (Fig. 6).

However, sometimes iPSCs fail to reproduce the same effect successfully. This may be due to the fact that it is difficult to create pluripotent environment within a multipotent counterpart. During their lifetime, the adult humans are constantly being exposed to deleterious environmental impacts of a multiplicity of anthropogenic substances, number of drugs, chemicals, and pollutants which may induce toxic effects. So is it wise to use embryogenic cell-based models (ES cells and iPSCs cells) to predict the toxicity that is encountered by adult individuals? It is reported that neural stem cells or progenitor cells may be relevant models for alternative developmental neurotoxicity (DNT) testing [31]. When xenobiotic agents interfere with progressive development and growth, they alter cellular growth and differentiation, leading to permanent or temporary changes in tissue or organ structure and function, i.e., disease, disorder, and developmental malformations. All these mutually exclusive events are controlled by expression of a unique set of genes, i.e., influenced by many environmental (physical, chemical and biological) factors [32].

When stresses are intricated by any stressors (toxicants), this disrupts cell-to-cell communiqué and provokes an adaptive response and ends in non-adaptive consequences. All these phenomena influence stem cells niche and deregulate cell cycle progression, cellular function, intracellular communiqué, and signaling pathways. These pathways can activate or inactivate specific gene that regulates transcription of extant proteins or transcription factors (FTs) involved in proliferation, differentiation, apoptosis, stress responses, and senescence. But how do the toxic agents intricate teratogenesis, carcinogenesis and mutagenesis in targeted tissues? This may be due to the fact that toxicants involve initiation or inhibit intracellular signaling cascades that trigger acetylation, deacetylation, and methylation of histones leading to DNA damage by epigenetic modification of chromatin [33]. All these events may happen due to the fact that these toxicants disturb gap junction intercellular communication (GJIC) that maintains tissue homeostasis and controls cellular function, such as growth, differentiation, development, and apoptosis. Gap junctions are plaquelike protein structures that form contiguous channels between cells allowing for the passive diffusion of low molecular weight metabolites and second messengers between the molecular weight of 1-1200 Dalton (Da). Each channel is made up of two connexons, each residing in separate contiguous cells. The connexon is made up of six subunits that are termed as connexins [34]. Due to the central role of intercellular signaling through gap junctions, GJIC plays a significant role in coordinating signaling events that control gene expression. This property makes it an ideal biological endpoint to monitor the toxic effects of environmental agents, toxins and potential health hazards of pharmaceuticals. Gap junction communication through connexin-mediated junctions' connexin 43 (Cx43) plays a major role in development and differentiation of bone development. The extracellular communication or "stromal-epithelial-type" interactions trigger intracellular communication signals to modulate GJIC between either homologous or heterologous cells within tissues [32]. GJIC can be modulated either reversibly or irreversibly, by most, if not all, "tumorpromoting chemicals." Inhibition of GJIC has been postulated to mediate via non-genotoxic carcinogenic mechanism. This mechanism may relate to tumor promotion and progression. Recent studies demonstrate that inhibition of GJIC in rats and mice is well correlated with induction of both liver tumors and markers for peroxisomal proliferation which result from excess deposition of phthalate esters in the liver. However, species-specific differences exist in response to analog of phthalate esters as shown by studies with DEHP and diisononyl phthalates (DINP). However, GJIC was unaffected in some mammalian species hamsters 


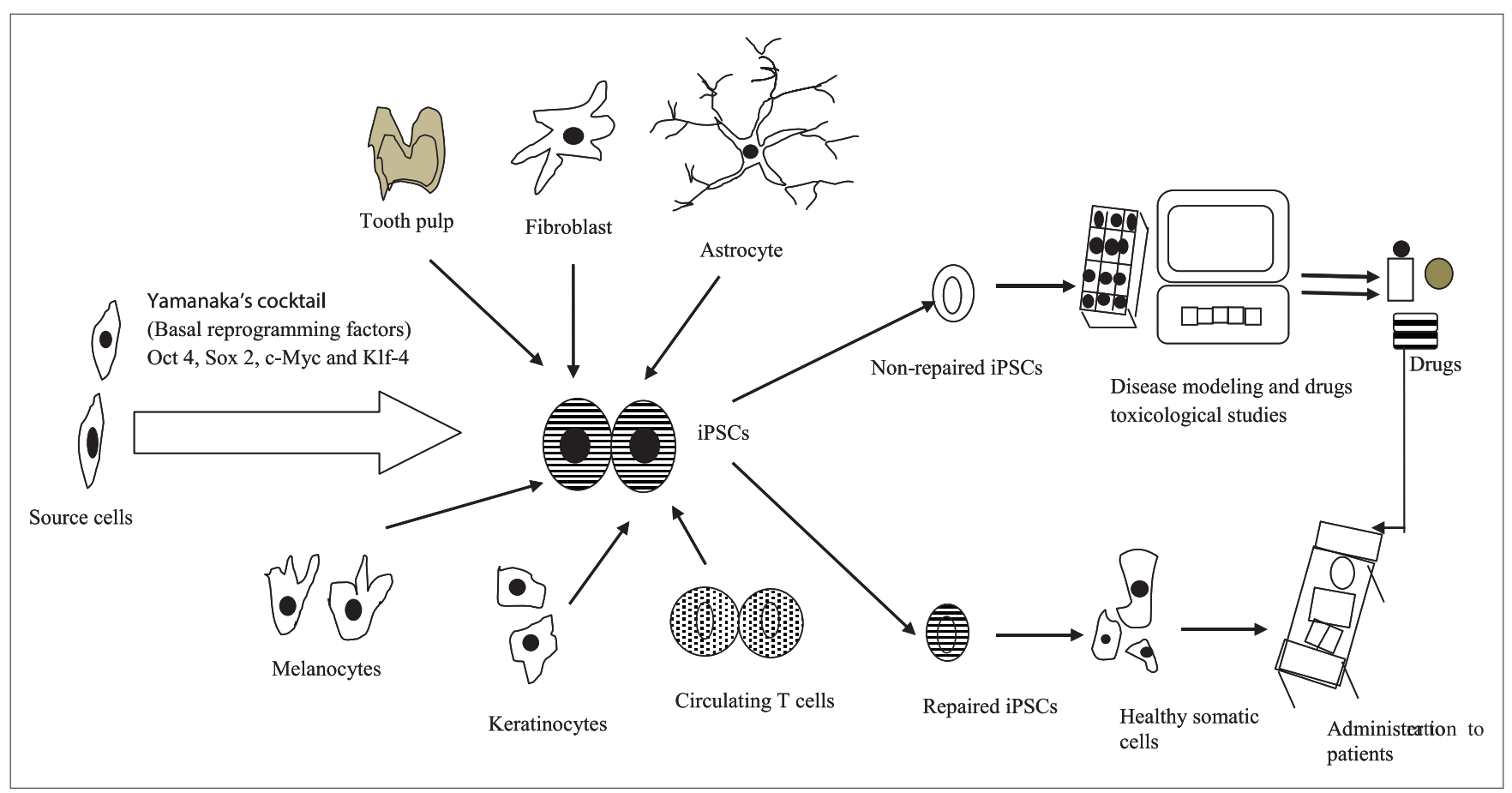

Fig. 6: Application of human-induced pluripotent stem cells in basic and applied research

and primates including humans in which phthalate treatment does not induce peroxisomal proliferation. In vitro studies which extended the database to include human liver cells mirrored the in vivo situation. Peroxisomal proliferation has been characterized as a species-specific process essential for phthalate-induced rodent liver tumor induction. Thus, the GJIC data along with those from studies of peroxisomal proliferation support the view that the carcinogenic effects of DEHP and DINP in rodents are not relevant to humans [35]. These evaluated data on cells from other species cannot also explain the in vivo situation of human in the presence of any toxic agent. So currently, it is a prime concern for the researchers associated with pharmacokinetics and toxicological studies to design a reliable test system which sufficiently mirrors the in vivo situation of human.

But how to determine the toxic effects of any toxicant on cells, tissues or organs? The ability of chemicals with tumor-promoting or tumor-inhibiting activity to modulate gap junctional intercellular communication have been detected with two most extensively used assays, namely (1) metabolic cooperation assays and (2) dye-transfer assays [36]. In metabolic cooperation assays, a population of donor cells is incubated in the presence of an excess of a radiolabeled precursor (typically uridine) and then cocultured with unlabeled recipient cells. Under such conditions, quantitative autoradiography enables evaluation of the transfer of the resulting metabolites from loaded to unloaded cells as a function of time. In this type of experiment, coupling is demonstrated by the autoradiographic labeling of the cytoplasm of recipient cells due to the incorporation in their ribonucleic acid of radiolabeled nucleotide synthesized within donor cells and transferred across $\mathrm{Cx}$ channels. Radioactive nucleotide transfer allows for a direct evaluation of the permeability of $\mathrm{Cx}$ channels to endogenous molecules. The scrape loading/dye transfer technique is a simple functional assay for the simultaneous assessment of GJIC in a large population of cells [37]. Dye-transfer assays measure exchange of fluorescent dye from loaded cells to adjacent cells. It is demonstrated that a number of factors play an important role for routine screening of toxic agents. These include the requirement of biotransformation for some agents to exert effects on gap junctions. The tumor promoters and tumor inhibitors affect gap junctional permeability that influences many physiological mechanisms like protein kinase activation, changes in proton and $\mathrm{Ca}^{2+}$ intracellular concentration and oxyradical production [36]. Growth factors, hormones, extracellular matrix, and cytokines can also block GJIC [38]. In many AS cells, neither the connexin genes are expressed nor are the gap junctions functional [39]. The cancer cells completely lose expression of connexin gene. Hence, measurement of GJIC plays a significant role in determination of toxic level [40]. This involves the transfer of a low molecular weight fluorescent dye $(<1000 \mathrm{Da})$ between contiguous cells [41]. It is thought that chronic disruption of GJIC may release some factors that favor clonal expansion and ultimately tumor formation [42]. Reduced expression of GJs following treatment with nongenotoxic carcinogens appears to affect specific target organ $[43,44]$. Due to exposure to mutagens or carcinogens, xenobiotic compounds and EDs the immune response hikes to initiate intracellular signaling cascades and releases various bioactive secreting factors (Fig. 7).

Available literature suggests that $[6,32,45]$ the different types of stem cells are involved in toxicity testing and screening of organ-specific toxicity (Fig. 8).

\section{MSCS AND TOXICOLOGICAL STUDIES}

The mesenchyme is an embryonic connective tissue which is derived from the mesoderm (the middle embryonic layer) that harbors mesenchymatous cells which have a high rate of division and the ability to spread and migrate in early embryonic development between the ectodermal and endodermal layers. The MSCs are heterogeneous multipotent stem cells which play a pivotal role in the development of all evolving structures and organs from the mesenchyme during ontogeny [46]. MSCs lie at the top of the mesenchymal cell hierarchy and progress through discrete stages of differentiation in an orderly manner to give rise to functionally and phenotypically mature tissues, including bones, smooth muscles, tendons, and cartilages [47]. In general, these MSCs are considered to originate in the mesenchyme, but embryonic MSCs have recently been shown to be derived also from the neuroepithelium and neural crest. However, it remains unclear whether ontogenically distinct MSCs are endowed with specific functions. MSCs are multipotent stem cells residing in almost all postnatal organs and tissues. Like other stem cells, they have unique properties such as self-renewal, unlimited proliferation ability, and plasticity to generate various cell types. Earlier it was assumed that MSCs can differentiate only to mesodermal lineages (osteocytes, chondrocytes, and adipocytes) 


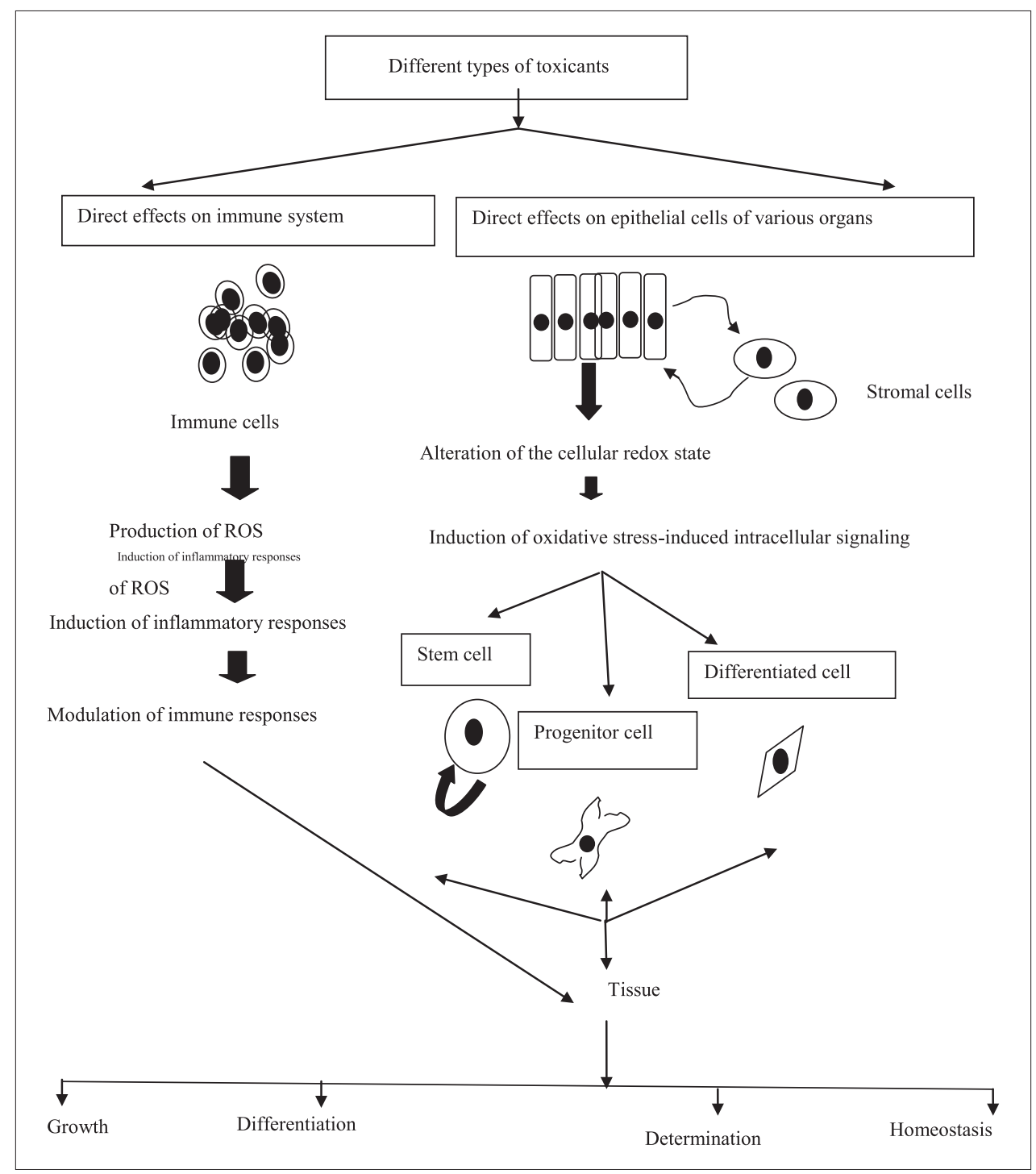

Fig. 7: Different physical, chemical, or biological agents affect normal cellular functions

but now it is well demonstrated that these can fabricate into distinct end-stage cell types of 3 primary germ layers such as mesodermal (bone, cartilage, muscle, bone marrow stroma, tendon/ligament, fat, dermis, and other connective tissues), ectodermal (epithelial, glial, and neural), and endodermal (hepatocyte and islet cell) lineages in in vitro and in vivo condition. Friedenstein et al. (1970) first reported the existence of non-hematopoietic multipotent precursor cells in bone marrow (BM) with skeletal and adipose potential [48]. This rare population also exists in adipose tissues, skeletal muscles, umbilical cord blood (UCB), placenta and Wharton's jelly tissues, UCB and several blood sources such as peripheral blood, menstrual blood of female other than BM. These cells can be derived, expanded, and manipulated in vitro. MSCs express the molecular markers which include CD90, CD105, and CD73 and fail to express the markers such as CD34, CD45, and CD14. Contemporary to other available cell lines, MSCs also express pluripotent genes that include the TFs Oct4, Sox2 and Nanog, which are normally express by hES cells [49]. Hence, this could be considered as safe alternative of ES cells and iPSCs. MSCs are special kind of stem cells that oscillate between pluripotency and multipotency. That is why MSCs are promising cell source for cellular therapy, tissue engineering, and regenerative medicine. This may be due to their inherent nature and plasticity to differentiate into multiple lineages. These have the ability to integrate into the host tissues without showing immune rejection by host immune system. This may be due to the fact that MSCs secrete a broad spectrum of bioactive macromolecules that are immune- regulatory and immune-suppressive in nature. This makes them most favorable choice for autogenic and allogenic transplantation [47]. These cells can be used to renew, repair and reform the vulnerable tissues, and therefore, widely applied to therapeutic cloning, tissue engineering, and regenerative medicine. The characteristic features of MSCs such as fibroblastic morphology, adherent nature, spheroid formation ability, easy genetic manipulation, and susceptibility to molecules that modify their natural behavior make them efficient candidate for non-therapeutic clinical research especially for pharmacological and toxicological studies. The spheroids may mimic three-dimensional (3D) organotypic models. These 3D in vitro culture models are expected to be relevant representative of the in vivo environment. Are the spheroids able to replace EBs needed for embryotoxicity and teratogenicity assay? Human MSCs can make cardiac connexins (Cx43, Cx 40 and Cx 45) and form gap junctional complex. It is recently reported that amniotic fluid-derived stem cells differentiate into cardiomyocyte-like cells and form gap junctions when directly mixed and cultured with neonatal rat ventricular myocytes [50]. Similar to other cells, toxic agents also affect viability, morphology, and function of MSCs. The effects of toxic agents on MSCs derived from different sources lead to undesirable consequences (Fig. 9).

A plethora of experimental works unequivocally established that MSCs can directly differentiate into neurons, glial cells, cardiomyocytes, and liver-specific cells (hepatocytes, pancreatic $ß$ cells). According to a 


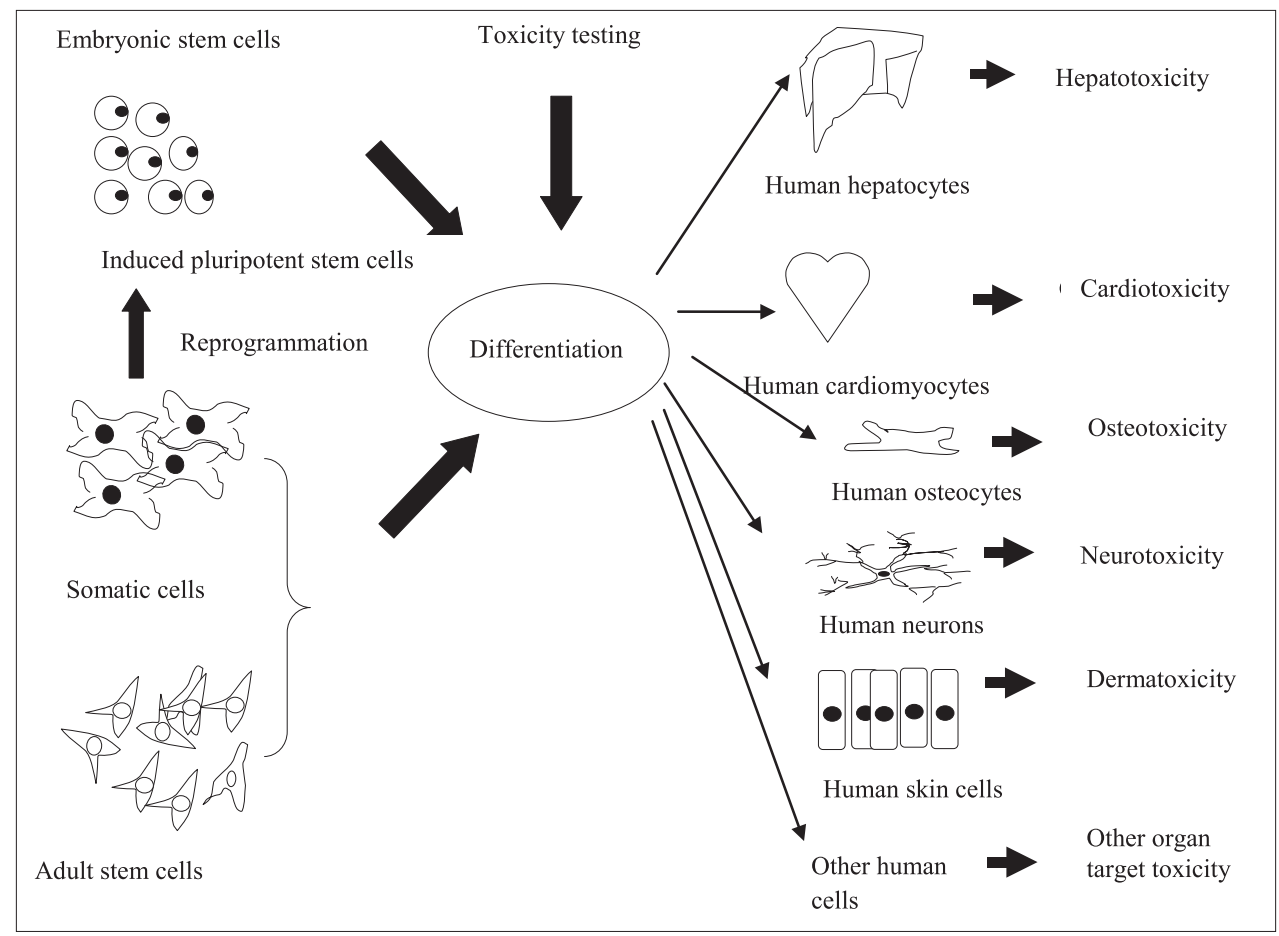

Fig. 8: Role of stem cells in screening of toxicity

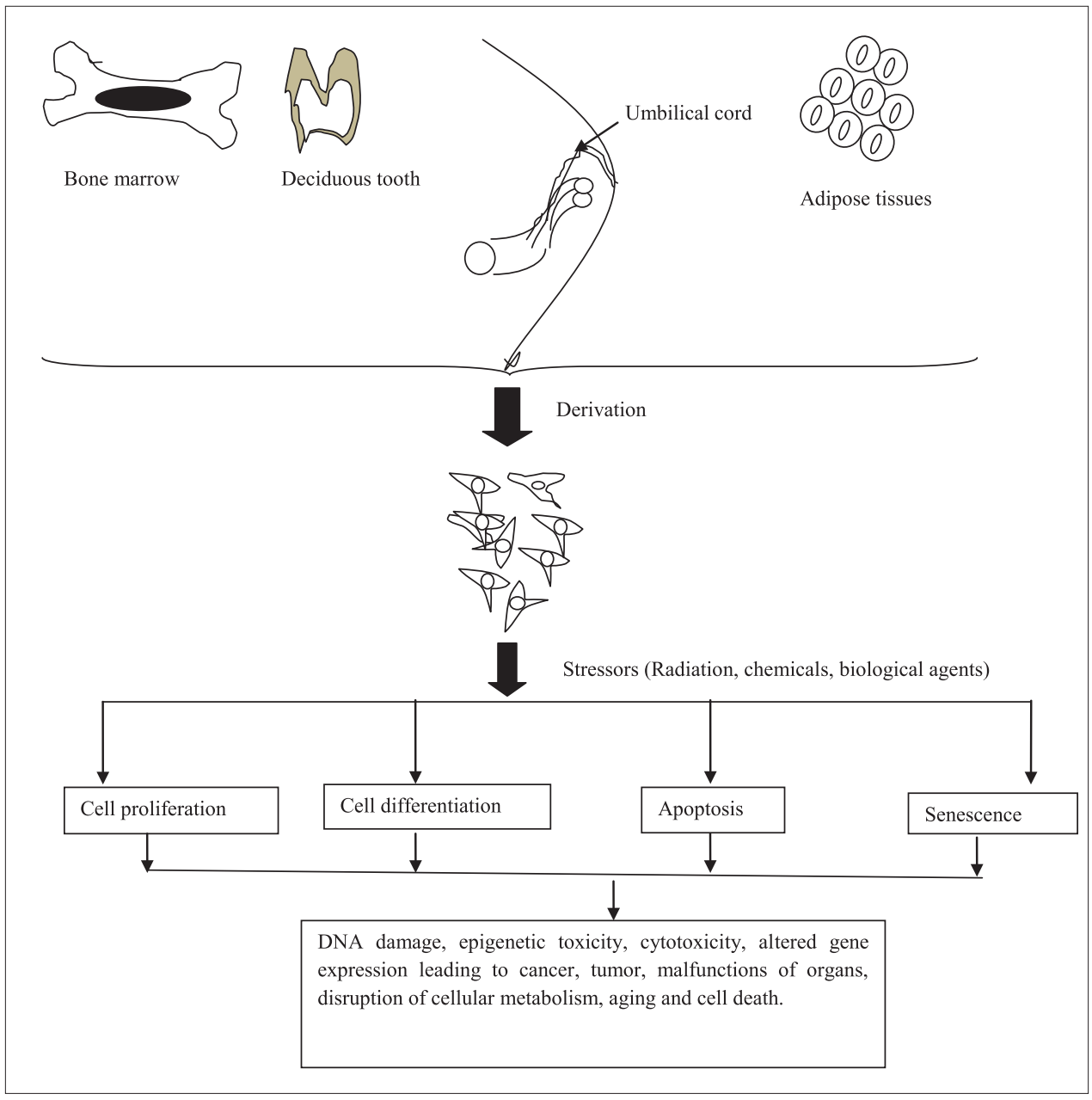

Fig. 9: Induced toxicity by different stressors on in vitro cultured mesenchymal stem cells 
report that human bone marrow stem cells could able to differentiate to male GCs [51]. These bone marrow cell-derived GCs also express the known molecular markers of primordial GCs, such as fragilis, stella, Rnf17, Mvh and Oct4 as well as molecular markers of spermatogonial stem cells and spermatogonia including Rbm, c-Kit, Tex18, Stra8, Piwil2, Dazl, Hsp90 alpha, beta 1- and alpha 6-integrins. Recent study by Latifpour et al. [52] report that human umbilical cord (hUCMSCs) can trans-differentiate into primordial like GCs (PGCs) when in vitro culture was performed under specific condition (bone morphogenetic protein 4 followed by retinoic acid). Hence, MSCs can be efficiently utilized to study mechanisms and pathways of different toxicants provoking etiology of many diseases, toxicity testing, evaluation of cytotoxicity and genotoxicity of pharmaceuticals and toxicity screening of chemicals that induce neurotoxicity, cardiotoxicity, hepatotoxicity, reprotoxicity, and drug discovery [53]. For example, development of anti-obesity drugs requires adipocytes that can be used to test whether any chemicals and toxicants can affect this process. Scanu et al. [54] report that hMSCs can be used for acute toxicity testing of chemicals.

\section{NEUROTOXICITY}

The complexity of the developing human brain complicates efforts to assess DNT in vitro, as the underlying mechanisms may include selective cell death, delayed or aberrant differentiation, suppressed neurotransmission, disruption of the blood-brain barrier, or modulation of inflammatory signals by glial or microglial cells. Thus, an in vitro model to predict human neurotoxicity needs to recapitulate a diversity of cellular interactions during human brain development and should be reproducible both within an experiment and between experiments performed on different days or at different sites. The studies impressively demonstrate that capacity of neuronal precursor cells prepared from self-assemble 3D "organoids" and hMSCs offer a consistent, scalable source for diverse neural cell types including neuron, glial cells, and astrocytes in the presence of appropriate inducers. Recent report suggests that hUCMSCs differentiate into neural-like progenitor cells and matured oligodendroglial-like lineage when cultured in neurobasal medium supplemented with B27, $10 \mathrm{ng} / \mathrm{ml}$ of human recombinant bFGF, platelet-derived growth factor-AA and $100 \mathrm{ng} / \mathrm{ml}$ of Sonic Hedgehog [55,56]. Toxic effects of chemical compounds, environmental factors, naturally occurring substances, anthropogenic agents, and EDs can lead to neurotoxicity. Neurotoxicities may express as neuropathologic condition or as altered neurocthemical, electrophysiological or behavioral functions which, in turn, leads to temporary or permanent harm to the central or peripheral nervous system. Environmental toxicants or pharmaceutical agents can influence excitotoxic processes which exaggerate their deleterious effect. In case of excitotoxicity (a specific form of neurotoxicity), excessive stimulation of the neuron occurs due to spinal cord injury, stroke, or traumatic brain injury during which neurotransmitters like glutamate and similar substances are responsible for damage and death of nerve cells that can be measured by several assays (Fig. 10).

The neurotoxicity test model allows studying the adverse effect of drug candidates on neuronal cells with the help of neurotoxicity assays for screening of compounds. This test system allows the reduction in production cost of preclinical development of drugs. Impaired calcium signaling and calcium measurements may be important criteria to know about neurotoxic agents. There is a decrease in depolarization, elicited by calcium elevation that accompanies the release of the specific neurotransmitter synthesized by a given neuron. Thus, this outcome provides valuable information about the toxicity of an uncharacterized compound to assess the toxicity of various compounds. Comparing cytotoxic or apoptosis-triggering effects of a given compound at different stages of neuronal differentiation also provide useful information about the severity of that particular agent. The toxicity of corticosteroid used in ophthalmological therapy of treatment of age-related macular degeneration (AMD) has been tested using MSCs. For this, MSCs were seeded with triamcinolone acetonide (9a-fluoro-16a-hydroxyprednisolone, TA), intravitreal triamcinolone, and dexamethasone at different concentration $(0.01 \mathrm{mg} / \mathrm{mL}$,
$0.1 \mathrm{mg} / \mathrm{mL}$, and $1.0 \mathrm{mg} / \mathrm{mL}$ ) [57]. The study of evaluation of drug toxicity reveals that a strong relationship exists between concentration of drugs and time with viability of MSCs. As the concentration of drugs and duration increases the viability decreases. This study demonstrates the need to use low concentration corticosteroid in pharmaceutical formulation of AMD. The developing brain is particularly vulnerable to toxic agents, even at exposure levels that have no lasting effects in the adult nervous system. Therefore, DNT assessment is a serious concern for environmental chemicals, drugs and new chemical entities. By using adipose tissue-derived MSCs (AT-MSCs) Qasemian Lemraski et al. [58] demonstrated that lead $(\mathrm{Pb})$ is a potent DNT. This study further explains how MSCs could be utilized to determine toxic potential of chemicals. In vitro cytotoxicity tests are also typically carried out with transformed, immortalized cell lines, or primary cells. Immortalized cells are readily available and easily maintained, although they usually show anomalous behavior and phenotypes, which do not reflect the mechanisms observed in their normal homologous cells. Primary cells are indeed considered a better option as model systems for predicting toxicological behavior, although they are limited in quantity and suffer from batch-to-batch variation due to the need to isolate them freshly for each study. In particular, hMSCs have never been adopted to develop in vitro model systems for acute toxicity tests of chemicals. Therefore, the main aim of the study was to verify the possibility of using hMSCs as an alternative method to estimate in vivo starting dose for acute toxicity. As suggested by ICCVAM, 12 reference chemicals were assessed in the present study and a Neutral Red Uptake assay was performed. It is reported for the first time that MSCs isolated from human bone marrow can undoubtedly be used to test acute neurotoxicity [55].

\section{CARDIOTOXICITY}

Cardiovascular disease is the lead cause of death worldwide. Every year 17 million people die of cardiovascular disease. Out of this 11 million die as a result of cardiac disease and 5.5 million deaths are related to stroke. It is estimated that myocardial infarction carries a mortality rate $7 \%$ (with aggressive therapy). Even more distressing condition record due to congestive heart failure causing mortality $20 \%$ in 1 year. The major agents responsible for cardiovascular diseases are hypertension, diabetes, stress, the chronic use of few drugs, cigarette smoking, elevated cholesterol, obesity, physical inactivity, and aging [59]. The spectra of cardiovascular diseases are amenable to therapeutic intervention via cell engraftment, organ transplants, and angioplasty. However, these treatments are far from the reach of common people. These costly treatments may be due to the fact that adult cardiomyocytes have a limited regenerative capacity, and their loss permanently results in impaired myocardial contractile function leading to loss of cardiac function and heart failure. In fact, some class of drugs (cardiotoxic agents) are responsible for cardiac damage (Table 1).

Efforts are being made to develop different ways of treating cardiovascular diseases that involve not only producing immunocompatible cardiomyocytes but also establishing more sophisticated cellular drug discovery and test systems. Much faster heart rate in humans makes the rodent model unsuitable to mimic the basic physiological functions of heart of human. The contractile nature and function of in vitro differentiated cardiomyocytes have additional advantage as these respond in similar manner as fetal cardiomyocytes to the drugs. Hence,, these ultimately provide an optimum homogenous cell culture system for screening of cardiotoxic agents and improved high-throughput drug discovery process. Several protocols and strategies have been reported for in vitro differentiation of cardiomyocytes from MSCs. Cultured MSCs differentiate into beating cardiomyocytes in the presence of 5-azacytidine [60]. It is well documented that the compounds that do not interfere with ion channel functionality also causes cardiotoxic insults. In many cases of cardiotoxicity, a direct interaction of drugs with specific ion channels expressed by the cardiomyocytes leads to alteration in ion conduction through these specific channels. Effects of the agents like drugs and chemicals on potassium currents could lead to QT-prolongation, 


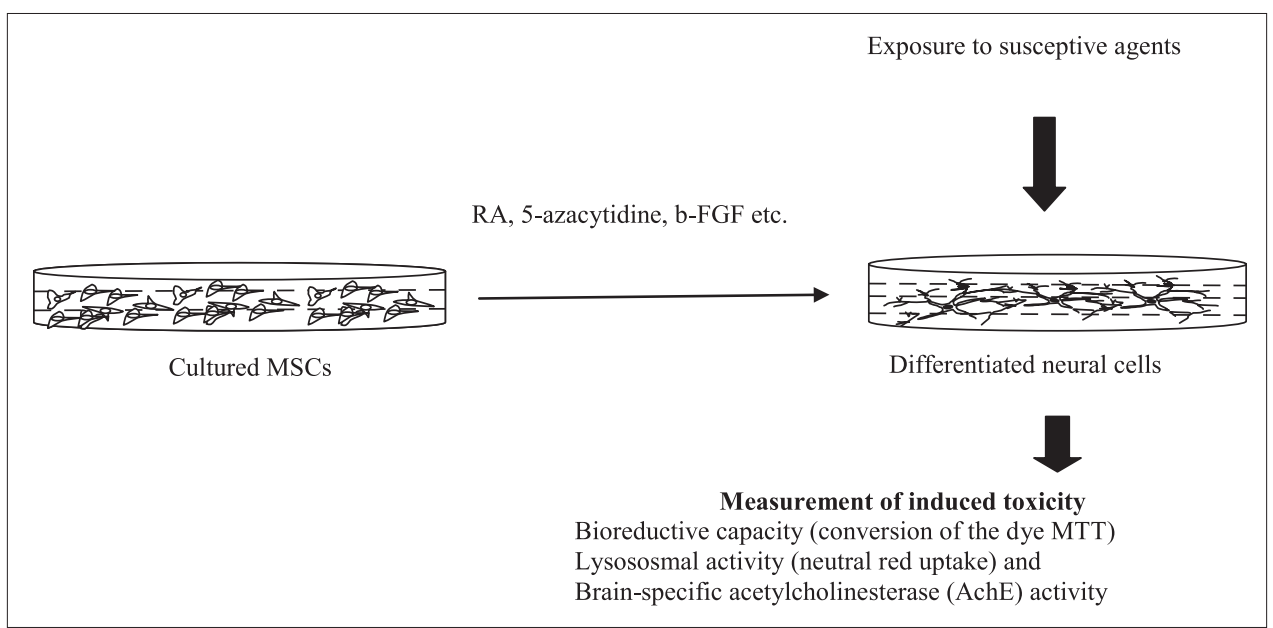

Fig. 10: Neuronal differentiation of mesenchymal stem cells and measurement of neurotoxicity by different assays

Table 1: Some cardiotoxic agents

\begin{tabular}{llll}
\hline Class of drugs & Drugs & Induced toxicity & Degree of incidence \\
\hline Anthracyclines & Doxorubicin & Acute - arrhythmias & Very frequent \\
Alkylating agents & Cyclophosphamide & Myocarditis, CHF & \\
& Ifosfamide & Myocarditis, CHF & \\
& Cisplatin & Ischemia, CHF & Common \\
Antimetabolites & 5-Fluorouracil & Ischemia & Rare \\
& Cepecitabine & CHF & Rare \\
Other & Cytarabine & Ischemia & Very frequent in Europian country and USA \\
\hline
\end{tabular}

CHF: Congestive heart failure

potentially fatal arrhythmias and sometimes cardiomuscular damage without affecting ion channels [61].

Unfortunately, modern training in toxicology and pharmacokinetics is directed primarily at specific ligand-receptor interactions at the expense of system physiology. Current physiological testing strategies may potentially miss cardiac effects that manifest chronically, vascular and microvascular effects. It results from toxicity initiated in other tissues and microvascular physiology and toxicology in the context of model development, application, and underlying pathology. Cancer chemotherapies might cause cardiomyocyte apoptosis and dysfunction. However, different chemotherapeutics might have different toxicity induction mechanisms. This new approach utilizes a dual-channel automated image cytometer that allows for simultaneous measurement of the cardiomyocyte action potential and calcium transient using voltage and calcium-sensitive dyes. ESC- and iPSCderived cardiomyocytes have recently been used to study doxorubicintriggered toxicity [62]. MSCs-derived cardiomyocytes are suitable to study the effects of compounds which do not interfere with the ion channel functions but still cause cardiotoxicity. Doxorubicin, which belongs to the anthracycline family, has been proven to be effective in different tissue-derived cancer diseases, including cancer of the breast, lung, stomach, bladder, and skin. Despite the anti-tumoral properties of doxorubicin, myelosuppression, and particularly cardiotoxicity restrict its clinical use [63]. Doxorubicin also induces toxic effect in endogenous MSCs [64]. It is reported that BMMSCs, isolated from rats that receive doxorubicin, show slower proliferation rate and lower differentiation capacity, decreased connexin-43 production and hindered MSCs capacity to respond to cardiomyogenic differentiation stimuli [65]. So considering above cases, the conclusion can be drawn that MSCs could be a better option to detect cardiotoxic agents. Two clinically decisive biomarkers of cardiac damage that are sensitive indicators for doxorubicin-induced toxicity have been studied. Troponin $\mathrm{T}(\mathrm{TnT})$ is a useful biomarker for studying drug-induced toxicity effects on cardiac cells. After induction of doxorubicin, MSCs-derived cardiomyocytes released detectable levels of cardiac TnT and fatty acid-binding protein 3 in a dose-dependent manner [62]. Based on the availability of very sensitive and rapid analytical tools for these biomarkers, the assay lends itself well to miniaturization and high-throughput formats.

\section{HEPATOTOXICITY}

Culture of 3D tissue (in vitro) models can capture cell-cell and cellmatrix interactions that happen in in vivo counterpart [66]. Hepatocytes, the major cells of the liver, metabolize most compounds and thereby can be used to predict many pharmacological characteristics of a drug. It is still to improve and develop new models, in some areas such as hepatotoxicity. Presently, only hepatocyte-like cells (HLCs) expressing low levels of liver-specific markers, especially drug metabolizing and detoxifying enzymes are usually obtained, making them still unsuitable as metabolically competent cells for toxicity studies. The only exceptions are some hepatoma cell lines, particularly the HepaRG cell line that can differentiate from a bipotent progenitor stage to attain the functional capacity of normal adult hepatocytes in primary culture without losing the indefinite growth property of transformed cells [67]. Recently, Kwon et al. [68] report that differentiated HLCs from human AT-MSCs may be used as in vitro hepatotoxicity screening system. The toxic effect of arsanilic acid (Ars) and acetaminophen (AAP) on the hepatic development were determined. The hepatic differentiation from ATMSCs was confirmed by an increase in hepatic proteins or genes, the cytochrome P450 (CYP) activities, albumin secretion, and glycogen storage. The toxic effects of these hepatotoxicants on enzymatic activities of lactate dehydrogenase, alanine aminotransferase and aspartate aminotransferase do not significantly differ in response to Ars treatment. AAP treatment increases the activities of all enzymes in a dose-dependent manner, significantly at concentration of 2.5 and $5 \mathrm{mM}$ of AAP. The activities of CYP3A4 were not changed by AAP and Ars treatments. The activities of CYP1A2 were increased by AAP, whereas it was decreased by Ars treatment. This study demonstrates that AAP is more serious hepatotoxicant compared to Ars. Ionizing radiation is 


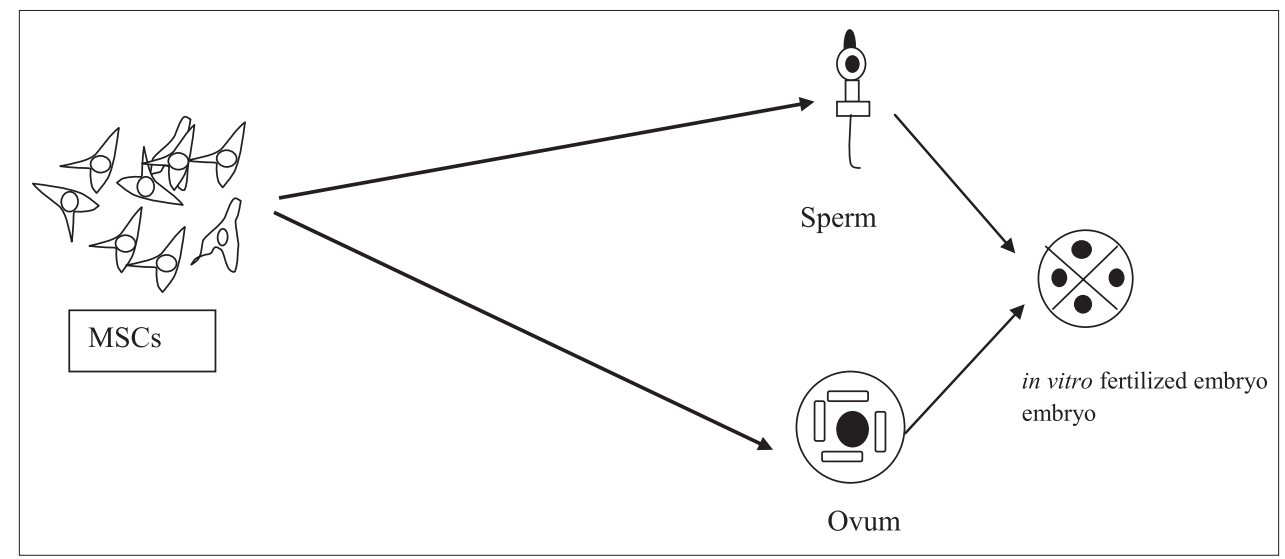

Fig. 11: Differentiation of mesenchymal stem cells into different reproductive cells

often used to treat malignancies such as breast cancer, lymphoma, Ewing sarcoma, soft tissue sarcomas and rectal and anorectal carcinomas. At the same time, radiation can induce chromosomal and gene mutation. This can cause epigenetic changes of genome leading to many diseases like skin cancer and induce oxidative stress which in turn alters gene expression. The experimental data put forth by Cao et al. [69] indicate that irradiation produces free radicals that adversely affect the survival of MSCs in both distal and proximal femora of mouse. Irradiation injury to the vasculatures and the microenvironment affects the niches for stem cells during the recovery period. This study is further supported by the investigation undertaken by Cruet-Hennequart et al. [70] on human bone marrow-derived MSCs.

\section{MSCS AND REPRODUCTIVE TOXICITY}

EDs are naturally occurring compounds or man-made substances that interfere with the function of endocrine system of the body. EDs may be any estrogen-like and anti-androgenic chemicals, environmental agents (e.g., PCBs, DDT, dioxin, and some pesticides) or biological stressors like oxidative stress or pharmacological agents like radiation and drugs. Exposure to such toxic agents at any stage of embryonic development right from maturation of gonads to post-natal development may alter the transporter expression and activity that maintain fetal growth [9]. These agents may bring epigenetic modification of placental gene expression and cause disability, neuronal disorders and abnormal behavior in offspring. MSCs represent a good model to assess reproductive toxicants as these can be used to recapitulate the different stages of development by differentiating into the cells associated with reproduction (Fig. 11).

Recent studies have shown that MSCs under appropriate conditions can differentiate into various cell types including GCs. These studies also show that MSCs without any induction express some GC-specific genes innately. Moreover, one report suggests that female MSCs have a greater tendency to differentiate into female instead of male GCs and male BM-MSCs appeared more prone to differentiate into male rather than female GC. Recently, it is investigated that a rat model with damaged ovaries caused by using an anticancer agent, cyclophosphamide was able to restore ovarian function after transplantation of A-MSCs. So, MSCs were shown to be capable of inducing angiogenesis and restoring the number of ovarian follicles and corpora lutea in ovaries [71]. hUCMSCs can differentiate into PGC under specific in vitro condition [53]. Thus, MSCs represent a good model to assess reproductive toxicants as these can differentiate into different reproductive cells recapitulating different stages of development of GCs. But do MSCs establish all in vivo developmental patterns and phases in in vitro environment?

\section{CONCLUSION}

Today, modern society is more dependent on the use of a wide range of different chemicals that provide substantial and highly appreciated benefits, but at the same time, they have the potential to cause damages to the environment and human health. Toxicogenomic technologies can facilitate the screening of chemical compounds for their ability to cause toxicity. Recently pharmaceutical industries develop the most advanced toxicogenomic screening applications. This reflects incentives to screen out undesirable properties and more efficiently identify drug candidates with the safest and the most efficacious profiles. Further research is suggested to develop new assay for screening chemical toxicity using MSCs that would help the public about the risk factors associated with that chemicals.

\section{ACKNOWLEDGMENTS}

Authors owe their thanks to the Department of Science and Technology, Government of India, for providing financial support vide reference number SR/WOS-A/LS-13/2016 dated 06.09.2016 under Women Scientist Scheme to carry out this work. Thanks are extended to Ms. Swati Singh, Ms. Manisha Mallick, Ms. Susree Sangita Pati and Ms. Sushreeta Puruseth for their critical reading and editing of the manuscript. Thanks are due to the Head, Post-Graduate Department of Zoology, Utkal University, Vani Vihar, Bhubaneswar- 751004 for providing the facilities.

\section{REFERENCES}

1. Krzyzosiak WJ, Sobczak K, Wojciechowska M, Fiszer A, Mykowska A, Kozlowski P. Triplet repeat RNA structure and its role as pathogenic agent and therapeutic target. Nucleic Acids Res 2012;40(1):11-26.

2. Il'yasova D, Kloc N, Kinev A. Cord blood cells for developmental toxicology and environmental health. Front Public Health 2015;3:265.

3. Baraldo M. The influence of circadian rhythms on the kinetics of drugs in humans. Expert Opin Drug Metab Toxicol 2008;4(2):175-92.

4. Assessment of the Safety and Efficacy of a New Thrombolytic Regimen (ASSENT)-Investigators. Efficacy and safety of tenecteplase in combination with enoxaparin, abciximab, or unfractionated heparin: The ASSENT-3 randomised trial in acute myocardial infarction. Lancet 2001;358(9282):605-13.

5. Wobus AM, Löser P. Present state and future perspectives of using pluripotent stem cells in toxicology research. Arch Toxicol 2011;85(2):79-117.

6. Suter-Dick L, Alves PM, Blaauboer BJ, Bremm KD, Brito C, et al. Stem cell-derived systems in toxicology assessment. Stem Cells Dev 2015;24(11):1284-96.

7. Ranganatha N, Kuppast IJ. A review on alternatives to animal testing methods in drug development. Int J Pharm Pharm Sci 2012;4(5):28-32.

8. Davila JC, Cezar GG, Thiede M, Strom S, Miki T, Trosko J. Use and application of stem cells in toxicology. Toxicol Sci 2004;79(2):214-23.

9. Andersen ME, Krewski D. Toxicity testing in the $21^{\text {st }}$ century: Bringing the vision to life. Toxicol Sci 2009;107(2):324-30.

10. Sharma P, Kumar P, Sharma R, Dhot PS. Futuristic scope of stem cells in medicine. Asian J Pharm Clin Res 2016; 9 (Suppl 1); 13-16.

11. Nishikawa S, Jakt LM, Era T. Embryonic stem-cell culture as a tool for developmental cell biology. Nat Rev Mol Cell Biol 2007;8(6):502-7.

12. Morrison SJ, Kimble J. Asymmetric and symmetric stem-cell divisions in development and cancer. Nature 2006;441(7097):1068-74.

13. Wobus AM, Holzhausen H, Jäkel P, Schöneich J. Characterization of a 
pluripotent stem cell line derived from a mouse embryo. Exp Cell Res 1984;152(1):212-9.

14. Evans MJ, Kaufman MH. Establishment in culture of pluripotential cells from mouse embryos. Nature 1981;292(5819):154-6.

15. Martin GR. Isolation of a pluripotent cell line from early mouse embryos cultured in medium conditioned by teratocarcinoma stem cells. Proc Natl Acad Sci U S A 1981;78(12):7634-8.

16. Thomson JA, Itskovitz-Eldor J, Shapiro SS, Waknitz MA, Swiergiel JJ, Marshall VS, et al. Embryonic stem cell lines derived from human blastocysts. Science 1998;282(5391):1145-7.

17. Wobus, AM, Holzhausen H, Jakel P, Schoneich J. Characterization of a pluripotent stem cell line derived from a mouse embryo. Exp Cell Res 1984;152(1):212-9.

18. Keller GM. In vitro differentiation of embryonic stem cells. Curr Opin Cell Biol 1995;7(6):862-9.

19. Li M, Pevny L, Lovell-Badge R, Smith A. Generation of purified neural precursors from embryonic stem cells by lineage selection. Curr Biol 1998;8(17):971-4.

20. Brüstle O, Jones KN, Learish RD, Karram K, Choudhary K, Wiestler OD, et al. Embryonic stem cell-derived glial precursors: A source of myelinating transplants. Science 1999;285(5428):754-6.

21. Pera MF, Reubinoff B, Trounson A. Human embryonic stem cells. J Cell Sci 2000;113:5-10.

22. Liu W, Deng Y, Liu Y, Gong W, Deng W. Stem cell models for drug discovery and toxicology studies. J Biochem Mol Toxicol 2013;27(1):17-27.

23. Hong EJ, Jeung EB. Assessment of developmental toxicants using human embryonic stem cells. Toxicol Res 2013;29(4):221-7.

24. Seiler AE, Spielmann H. The validated embryonic stem cell test to predict embryotoxicity in vitro. Nat Protoc 2011;6(7):961-78.

25. Xin F, Susiarjo M, Bartolomei MS. Multigenerational and transgenerational effects of endocrine disrupting chemicals: A role for altered epigenetic regulation? Semin Cell Dev 2015; 43, 66-75.

26. Schönborn F, Pokovic K, Wobus AM, Kuster N. Design, optimization, realization, and analysis of an in vitro system for the exposure of embryonic stem cells at $1.71 \mathrm{GHz}$. Bioelectromagnetics 2000;21(5):372-84.

27. Takahashi K, Yamanaka S. Induction of pluripotent stem cells from mouse embryonic and adult fibroblast cultures by defined factors. Cell 2006;126(4):663-76

28. Singh VK, Kalsan M, Kumar N, Saini A, Chandra R. Induced pluripotent stem cells: Applications in regenerative medicine, disease modeling, and drug discovery. Front Cell Dev Biol 2015;3:2.

29. Scott CW, Peters MF, Dragan YP. Human induced pluripotent stem cells and their use in drug discovery for toxicity testing. Toxicol Lett 2013;219(1):49-58.

30. Deshmukh RS, Kovács KA, Dinnyés A. Drug discovery models and toxicity testing using embryonic and induced pluripotent stem-cellderived cardiac and neuronal cells. Stem Cells Int 2012;2012:379569.

31. Tofighi R, Moors M, Bose R, Ibrahim WN, Ceccatelli S. Neural stem cells for developmental neurotoxicity studies. Methods Mol Biol 2011;758:67-80.

32. Kang KS, Trosko JE. Stem cells in toxicology: Fundamental biology and practical considerations. Toxicol Sci 2011;120 Suppl 1:S269-89.

33. O'Hagan HM. Chromatin modifications during repair of environmental exposure-induced DNA damage: A potential mechanism for stable epigenetic alterations. Environ Mol Mutagen 2014;55(3):278-91.

34. Evans WH, Martin PE. Gap junctions: Structure and function (review). Mol Membr Biol 2002;19(2):121-36.

35. Trosko JE, Chang CC. Nongenotoxic mechanisms in carcinogenesis: Role of inhibited intercellular communication. In: Hart RW, Hoerger FD, editors. Banbury Report 31: Carcinogen Risk Assessment: New Directions in the Qualitative and Quantitative Aspects. New York: Cold Spring Harbor Laboratory; 1988. p. 139-70.

36. Budunova IV, Williams GM. Cell culture assays for chemicals with tumor-promoting or tumor-inhibiting activity based on the modulation of intercellular communication. Cell Biol Toxicol 1994;10(2):71-116.

37. Babica P, Sovadinová I, Upham BL. Scrape loading/dye transfer assay. Methods Mol Biol 2016;1437:133-44.

38. Kielian T, Esen N. Effects of neuroinflammation on glia-glia gap junctional intercellular communication: A perspective. Neurochem Int 2004;45(2-3):429-36.

39. Yang YC, Wang SW, Hung HY, Chang CC, Wu IC, Huang YL, et al. Isolation and characterization of human gastric cell lines with stem cell phenotypes. J Gastroenterol Hepatol 2007;22(9):1460-8.

40. Upham BL, Weis LM, Trosko JE. Modulated gap junctional intercellular communication as a biomarker of $\mathrm{PAH}$ epigenetic toxicity: Structure-function relationship. Environ Health Perspect 1998;106 Suppl 4:975-81.

41. el-Fouly MH, Trosko JE, Chang CC. Scrape-loading and dye transfer. A rapid and simple technique to study gap junctional intercellular communication. Exp Cell Res 1987;168(2):422-30.

42. Trosko JE, Upham BL. The emperor wears no clothes in the field of carcinogen risk assessment: Ignored concepts in cancer risk assessment. Mutagenesis 2005;20(2):81-92

43. Mally A, Chipman JK. Non-genotoxic carcinogens: Early effects on gap junctions, cell proliferation and apoptosis in the rat. Toxicology 2002;180(3):233-48.

44. Mesnil M, Fitzgerald DJ, Yamasaki H. Phenobarbital specifically reduces gap junction protein mRNA level in rat liver. Mol Carcinog 1988;1(2):79-81.

45. Rohwedel J, Guan K, Hegert C, Wobus AM. Embryonic stem cells as an in vitro model for mutagenicity, cytotoxicity and embryotoxicity studies: Present state and future prospects. Toxicol In Vitro 2001;15(6):741-53.

46. Klein D. Vascular wall-resident multipotent stem cells of mesenchymal nature within the process of vascular remodeling: Cellular basis, clinical relevance, and implications for stem cell therapy. Stem Cells Int 2016;2016:10.

47. Nombela-Arrieta C, Ritz J, Silberstein LE. The elusive nature and function of mesenchymal stem cells. Nat Rev Mol Cell Biol 2011;12(2):126-31

48. Friedenstein AJ, Petrakova KV, Kurolesova AI, Frolova GP. Heterotopic of bone marrow. Analysis of precursor cells for osteogenic and hematopoietic tissues. Transplantation 1968;6(2):230-47.

49. Hassiotou F, Beltran A, Chetwynd E, Stuebe AM, Twigger AJ, Metzger P, et al. Breastmilk is a novel source of stem cells with multilineage differentiation potential. Stem Cells 2012;30(10):2164-74.

50. Connell JP, Augustini E, Moise KJ Jr, Johnson A, Jacot JG. Formation of functional gap junctions in amniotic fluid-derived stem cells induced by transmembrane co-culture with neonatal rat cardiomyocytes. J Cell Mol Med 2013;17(6):774-81

51. Nayernia K, Lee JH, Drusenheimer N, Nolte J, Wulf G, Dressel R, et al. Derivation of male germ cells from bone marrow stem cells. Lab Invest 2006;86(7):654-63.

52. Latifpour M, Shakiba Y, Amidi F, Mazaheri Z, Sobhani A. Differentiation of human umbilical cord matrix-derived mesenchymal stem cells into germ-like cells. Avicenna J Med Biotechnol 2014;6(4):218-27.

53. Sharma S, Venkatesan V, Prakhya BM, Bhonde R. Human mesenchymal stem cells as a novel platform for simultaneous evaluation of cytotoxicity and genotoxicity of pharmaceuticals. Mutagenesis 2015;30(3):391-9.

54. Scanu M, Mancuso L, Cao G. Evaluation of the use of human Mesenchymal Stem Cells for acute toxicity tests. Toxicol In Vitro 2011;25(8):1989-95.

55. Hennekens $\mathrm{CH}$. Increasing burden of cardiovascular disease: Current knowledge and future directions for research on risk factors. Circulation 1998;97(11):1095-102.

56. Leite C, Silva NT, Mendes S, Ribeiro A, de Faria JP, Lourenço T, et al. Differentiation of human umbilical cord matrix mesenchymal stem cells into neural-like progenitor cells and maturation into an oligodendroglial-like lineage. PLoS One 2014;9(10):e111059.

57. Nuzzi R, Gunetti M, Rustichelli D, Roagna B, Fronticelli Bardelli F, Fagioli $\mathrm{F}$, et al. Effect of in vitro exposure of corticosteroid drugs, conventionally used in AMD treatment, on mesenchymal stem cells. Stem Cells Int 2012;2012:946090.

58. Qasemian Lemraski M, Soodi M, Fakhr Taha M, Zarei MH, Jafarzade E. Study of lead-induced neurotoxicity in neural cells differentiated from adipose tissue-derived stem cells. Toxicol Mech Methods 2015;25(2):128-35.

59. Hennekens $\mathrm{CH}$. Increasing burden of cardiovascular disease: Current knowledge and future directions for research on risk factors. Circulation 1998;97(11):1095-102.

60. Balana B, Nicoletti C, Zahanich I, Graf E M, Christ T, Boxberger S, Ravens U. 5-Azacytidine induces changes in electrophysiological properties of human mesenchymal stem cells. Cell Research 2006;16:949-60.

61. Dick E, Rajamohan D, Ronksley J, Denning C. Evaluating the utility of cardiomyocytes from human pluripotent stem cells for drug screening. Biochem Soc Trans 2010;38(4):1037-45.

62. Andersson H, Kågedal B, Mandenius CF. Monitoring of troponin release from cardiomyocytes during exposure to toxic substances using surface plasmon resonance biosensing. Anal Bioanal Chem 2010;398(3):1395-402

63. Volkova M, Russell R $3^{\text {rd }}$. Anthracycline cardiotoxicity: Prevalence, pathogenesis and treatment. Curr Cardiol Rev 2011;7(4):214-20. 
64. Oliveira MS, Carvalho JL, Campos AC, Gomes DA, de Goes AM, Melo MM. Doxorubicin has in vivo toxicological effects on ex vivo cultured mesenchymal stem cells. Toxicol Lett 2014;224(3):380-6.

65. Ezquer F, Gutiérrez J, Ezquer M, Caglevic C, Salgado HC, Calligaris SD. Mesenchymal stem cell therapy for doxorubicin cardiomyopathy: Hopes and fears. Stem Cell Res Ther 2015;6(1):116.

66. Elliott NT, Yuan F. A review of three-dimensional in vitro tissue models for drug discovery and transport studies. J Pharm Sci 2011;100(1):59-74.

67. Guguen-Guillouzo C, Corlu A, Guillouzo A. Stem cell-derived hepatocytes and their use in toxicology. Toxicology 2010;270(1):3-9.

68. Kwon MJ, Kang SJ, Park YI, Yang YH, Bang SI, Park YH, et al. Hepatic differentiation of human adipose tissue-derived mesenchymal stem cells and adverse effects of arsanilic acid and acetaminophen during in vitro hepatic developmental stage. Cell Biol Toxicol 2015;31(3):149-59.

69. Cao X, Wu X, Frassica D, Yu B, Pang L, Xian L, et al. Irradiation induces bone injury by damaging bone marrow microenvironment for stem cells. Proc Natl Acad Sci U S A 2011;108(4):1609-14.

70. Cruet-Hennequart S, Drougard C, Shaw G, Legendre F, Demoor M, Barry $\mathrm{F}$, et al. Radiation-induced alterations of osteogenic and chondrogenic differentiation of human mesenchymal stem cells. PLoS One 2015;10(3):e0119334.

71. Takehara Y, Yabuuchi A, Ezoe K, Kuroda T, Yamadera R, Sano C, et al. The restorative effects of adipose-derived mesenchymal stem cells on damaged ovarian function. Lab Invest 2013;93(2):181-93. 